\title{
Avaliação da qualidade habitacional da arquitetura modernista: estudo de caso em Bauru-SP
}

The evaluation of housing quality in modernist architecture: case study in Bauru-SP

Evaluación de la calidad habitacional de la arquitectura modernista: estudio de caso en Bauru-SP

\author{
Marcos Felipe Alves da Silva \\ Mestrando, UNESP, Brasil. \\ marcosf_arch@yahoo.com.br

\section{Renata Braga Aguilar da Silva} \\ Mestranda, UNESP, Brasil. \\ renataaguilar@hotmail.com.br
}

Maria Solange Gurgel de Castro Fontes

Professora Doutora, UNESP, Brasil. sgfontes@faac.unesp.br 


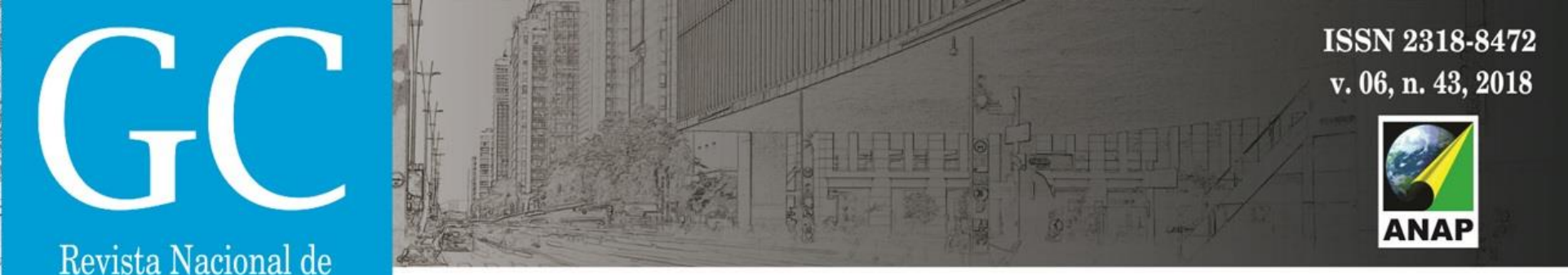

Gerenciamento de Cidades

\section{INTRODUÇÃO}

A modernidade na arquitetura esteve atrelada ao desenvolvimento industrial que desde o início do século XX já era constituída por bases positivistas, tendo o contexto histórico do período retratado pelo avanço tecnológico nas diversas áreas de conhecimento. Harvey (2008) expõe que a abolição de ornamentos das fachadas deu-se pelo culto "máquina e velocidade", surgindo nos primeiros projetos arquitetônicos: linhas retas, fachadas uniformes e funcionalidade na distribuição dos ambientes internos na moradia. Assim, o modelo ideal de projetos residenciais, moldado ao automóvel, no início do século XX segundo Banham (2006, p. 506): "[...] abre espaço para que um carro passe entre a parede e os pilotis que sustentam $o$ andar de cima".

O clima bélico das guerras mundiais, o poder de governos repressivos, o avanço do sistema capitalista, as desigualdades sociais dos países, e outros interferes impulsionaram a criação de uma nova vertente na arquitetura. Requena-Ruiz (2016) aponta que diversos estudos reforçam a preocupação dos arquitetos modernistas com o conforto térmico das habitações, como na avaliação das obras residenciais de Villa Curutchet de Le Corbusier, e Villa Chupin de André Wogenscky, comprovando que os arquitetos compreenderam as características naturais dos ambientes, apresentando: a orientação solar adequada dos edifícios, e o emprego de estratégias bioclimáticas, como brise-soleil e vegetação nas áreas externas.

Observa-se então, que através da arquitetura moderna, arquitetos compuseram o conhecimento das condições ambientais, como requisito básico para a elaboração de projetos residenciais. Cabral (2016) sobre as publicações de Lina Bo Bardi, arquiteta ítalo-brasileira, evidencia por meio da arquitetura modernista também tais considerações. Nesse caso, Bardi (1943, tradução nossa apud CABRAL, 2016, p. 8) expressa que:

\footnotetext{
[...] a forma e implantação do projeto arquitetônico são definidas pelos fatores naturais: "Montes, bosques, mares, rios, rochas, relvas e campos são fatores determinantes da forma da casa; o sol, o clima, os ventos determinam a sua posição, a terra circundante oferece o material para a sua construção; a casa nasce assim ligada à terra profundamente, as suas proporções são ditadas de uma constante, a medida do homem e ininterruptamente, com profunda harmonia, fluía sua vida" (BARDI, 1943, tradução nossa apud CABRAL, 2016, p. 8).
}

No presente artigo, aborda-se sobre a qualidade habitacional da arquitetura modernista brasileira, verificada através metodologia de Avaliação Pós-ocupação (APO) e Painel de Especialistas (PE) em um edifício multifamiliar (objeto de estudo) localizado na cidade de Bauru-SP.

No Brasil, desenvolveu-se a criação de uma linguagem particular (nacionalista) com o amadurecimento da arquitetura modernista entre anos 30 e 60, identificada mais precisamente em empreendimentos residenciais para classes de média e alta renda. Sobre essa questão, Bruand (2010, p. 377) ressalta que o contexto social e político do país "[...] 


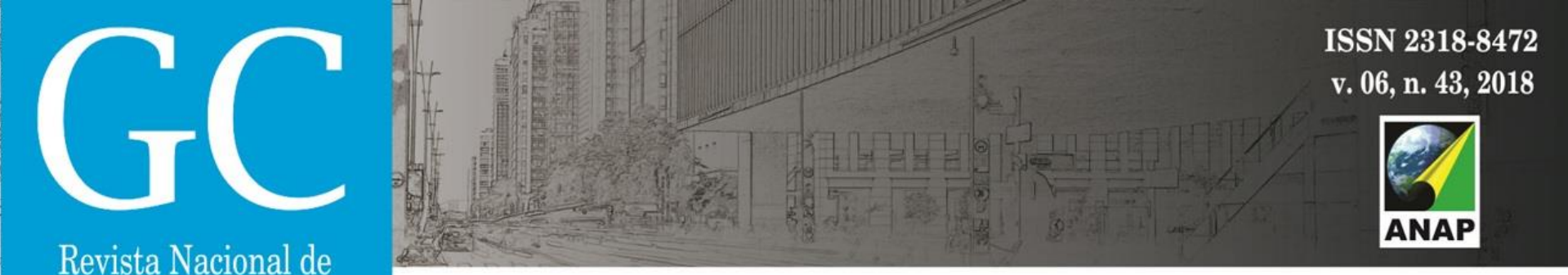

Gerenciamento de Cidades

permitiu o nascimento e desenvolvimento da nova arquitetura no Brasil levou-a naturalmente a procurar a riqueza decorativa; o desejo de impressionar o público ou a clientela [...]".

Uma das obras da arquitetura modernista que elucidam a citação acima é o Edifício Bretagne (Figura 1) do final da década de 50, autoria de João Artacho Jurado, localizado na cidade de São Paulo no bairro de Higienópolis. A concepção desse projeto pode ser notada pela sua composição expressiva de seus elementos arquitetônicos, que acompanha a tendência arquitetônica do período (terraço jardim) e utiliza uma linguagem própria (nacional).

Figura 1: Edifício Bretagne. Cores: verde (terraço jardim), azul (pastilhas das paredes) e amarelo (mosaico do piso)

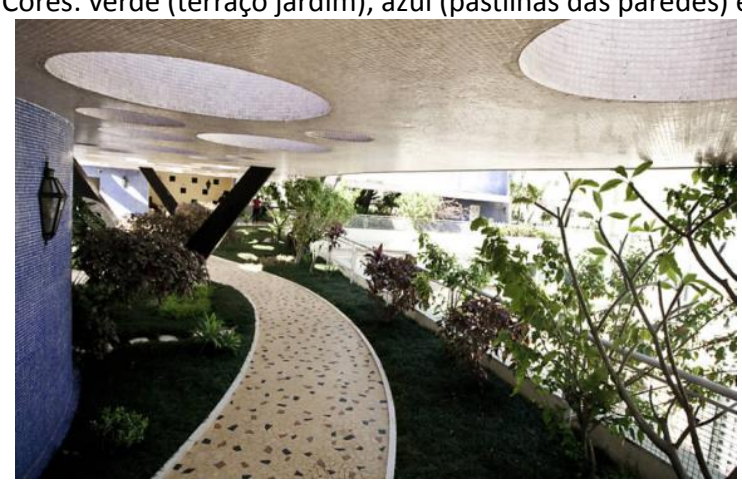

Fonte: VIZONI, 2011.

Além da estética, questões da esfera política e social do país também foram retratadas na concepção da arquitetura moderna. Bruand (2010) ressalta a atuação do arquiteto brasileiro João Batista Vilanova Artigas, que utilizou da influência da arquitetura moderna internacional como um meio de expressão, e releitura do contexto social de seu período.

Ainda sobre a qualidade arquitetônica no Brasil, Mahfuz (2002), analisa que a decadência da qualidade da arquitetura brasileira foi constatada após a inauguração de Brasília dando-se pelo declínio do amparo estatal na economia do país. Além do processo de globalização (abertura internacional do país) e da influência americana, que minimizaram o "conteúdo social" ao modo massificado de produção imobiliária na arquitetura, que para Artigas (2004, p. 52): “[...] sem maiores considerações de necessidades humanas, de vez que só se destinam a atender a bolsa de compradores, a ganância de aventureiros e a bolsa de empresários atraídos pela possibilidade de giro rápido de seus capitais".

$\mathrm{O}$ agravamento da qualidade habitacional dos apartamentos produzidos no fim do século XX até os anos 2000 na cidade de São Paulo para Villa (2004, p. 7) comprova, que: "[...] a partir dos anos de 1980, como é o caso da diminuição de áreas dos apartamentos ofertados no mercado, que em alguns casos podem chegar a até $30 \%$, ou mais dependendo do empreendimento - visto que já detectamos reduções de mais de $50 \%$ ".

Nesse artigo, ao utilizar a APO como metodologia para avaliação da qualidade habitacional, verifica-se que são poucas as investigações sobre a qualidade habitacional, via APO em edifícios residenciais multifamiliar da arquitetura modernista no panorama brasileiro, como as 


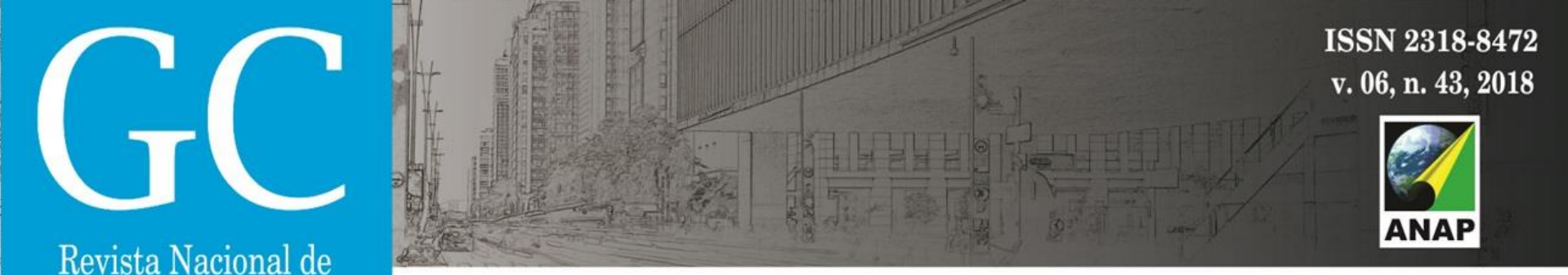

Gerenciamento de Cidades

escassas produções de: Zapatel (1993); Guellero e Salcedo (2006); Galvão (2007); Galvão e Ornstein (2008); Moisinho Filho (2008); Medeiros (2014).

Ainda com relação à metodologia de $\mathrm{APO}$, nota-se que não há especificidades em avaliar obras modernistas (bens patrimoniais). Na produção de Galvão, Ornstein e Ono (2013), imóveis "tombados", de valor histórico, ou com prazo de vida útil de 40 anos - conforme estabelecimento da Associação Brasileira de Normas Técnicas (2010) da NBR 15575 -, estão organizados em um único grupo intitulado por "Reabilitação de edifícios para habitação e APO". No pretexto etimológico que: "[...] muitas são as palavras que definem ações em edifícios antigos das quais destacamos retrofit, reforma, requalificação, restauro e reabilitação" (GALVÃO; ORNSTEIN; ONO, 2013, p. 46). A lacuna, assim presente, em APO justifica a necessidade em desenvolver pesquisas sobre a qualidade de obras (edifícios) modernistas, no caso da categoria habitacional, além da experimentação de novos métodos e técnicas que trabalhem de forma específica essa arquitetura no Brasil.

\section{OBJETIVOS}

O presente estudo tem o objetivo de avaliar a qualidade da arquitetura modernista, a partir das condições de: iluminação natural, conforto térmico, ventilação natural, acústica e dimensões dos apartamentos; utilizando-se para a investigação um edifício residencial multifamiliar (objeto de estudo).

\section{METODOLOGIA}

Utiliza-se a metodologia de Avaliação Pós-ocupação (APO) e Painel de Especialistas (PE). Os procedimentos metodológicos são organizados em partes: apresentação do objeto de estudo; tipo de pesquisa; população e amostra; coleta de dados; análise de dados.

\subsection{APRESENTAÇÃO DO OBJETO DE ESTUDO}

O objeto e estudo de caso é o Edifício Brasil Portugal, localizado na área central do município de Bauru-SP. O projeto é da década de 60 - tombado pelo Conselho de Defesa do Patrimônio Cultural de Bauru (CODEPAC) - de autoria do arquiteto português Fernando Pinho; expoente reconhecido pela qualidade arquitetônica de suas obras nas pesquisas de: Salcedo et al. (1999), Retto Júnior (2003), Ferraz (2003) e Pupim (2007). O prédio segundo Salcedo et al. (1999) foi construído em estrutura de concreto armado, apresenta fachada em formato retangular e implantação de acordo com as características climática e geográfica da cidade (Figuras 2 e 3). 


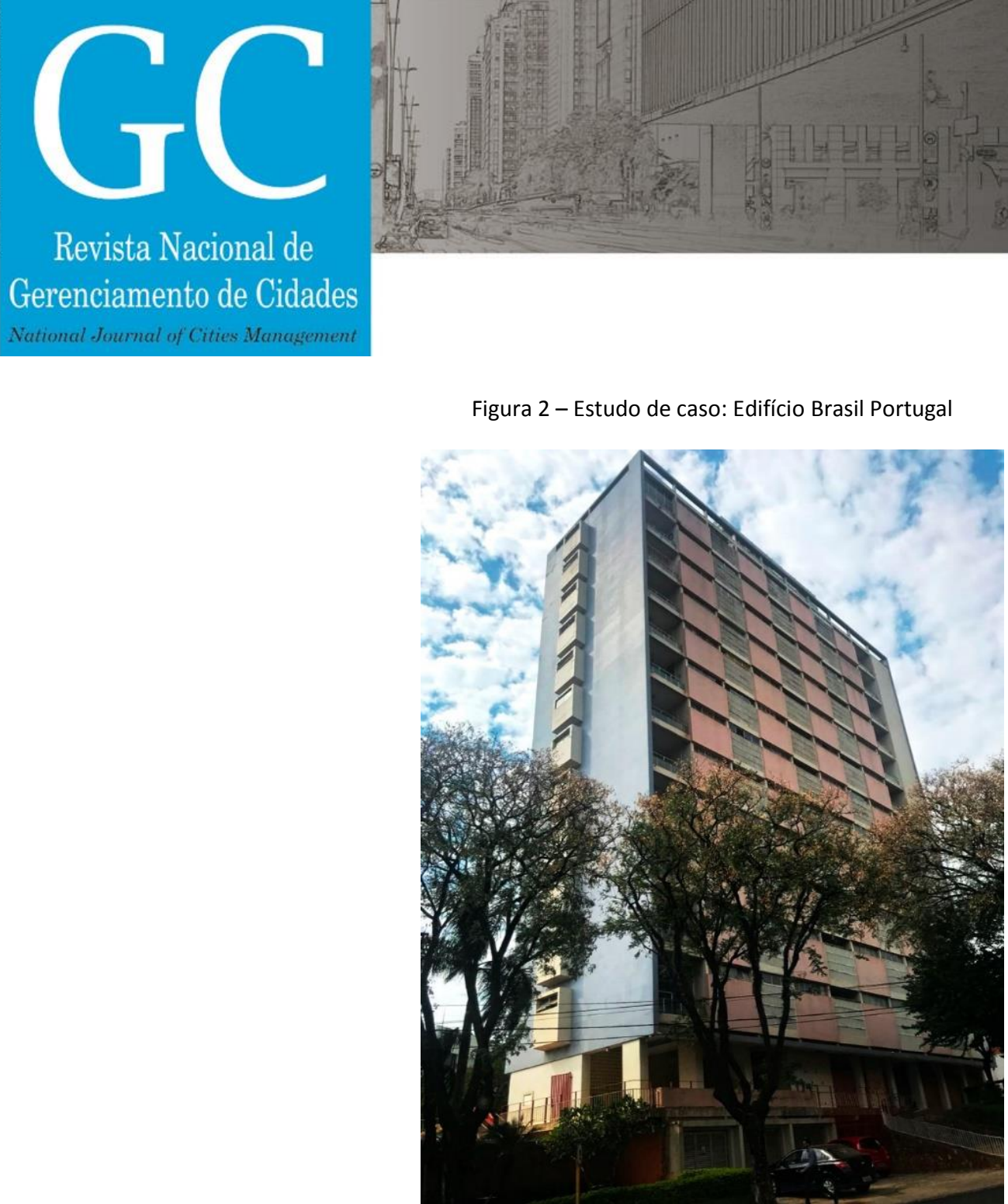

ISSN 2318-8472

v. 06, n. 43,2018

Fonte: AUTORES, 2018

Figura 3 - Edifício Brasil Portugal: arquitetura modernista brasileira da década de 60

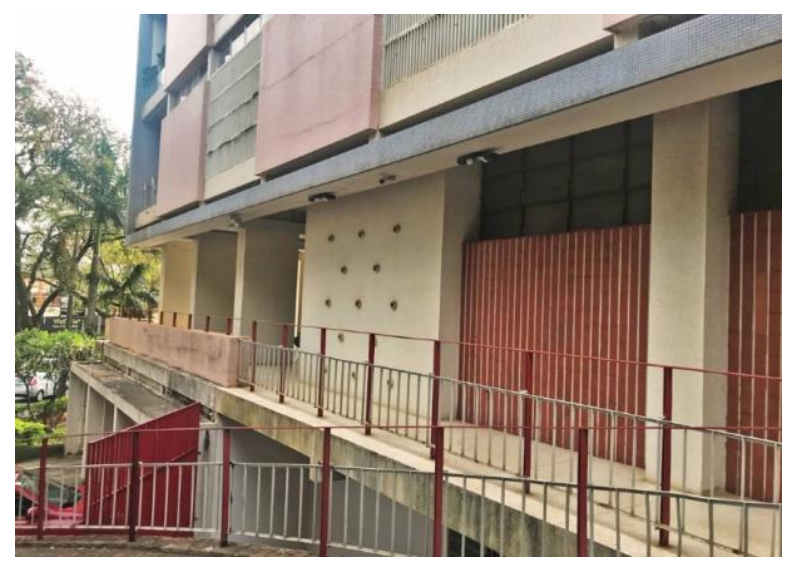

Fonte: AUTORES, 2018

A obra possui 15 pavimentos no total, sendo: 2 pavimentos em nível térreo de acessos diferentes devido ao perfil topográfico do terreno, nas Avenidas Rodrigues Alves e Nações Unidas, reunindo: garagens, dependência do zelador, depósitos e hall de entrada. Os demais andares são ocupados por apartamentos (12 pavimentos) e caixa d'água na cobertura (1 pavimento). 


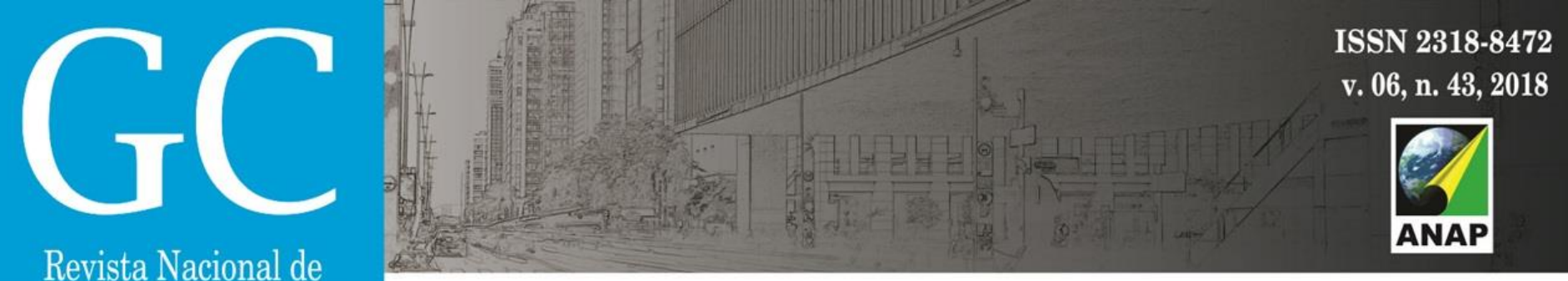

Gerenciamento de Cidades

Sobre os apartamentos ${ }^{1}$, cada pavimento reúne quatro unidades residências com três tipologias, de: dois apartamentos de 1 dormitório (tipologia A: cores azul e amarelo); um de 2 dormitórios (tipologia B: cor rosa) e um de 3 dormitórios (tipologia C: cor verde) (Figura 4):

Figura 4 - Planta baixo do pavimento tipo do Edifício Brasil Portugal
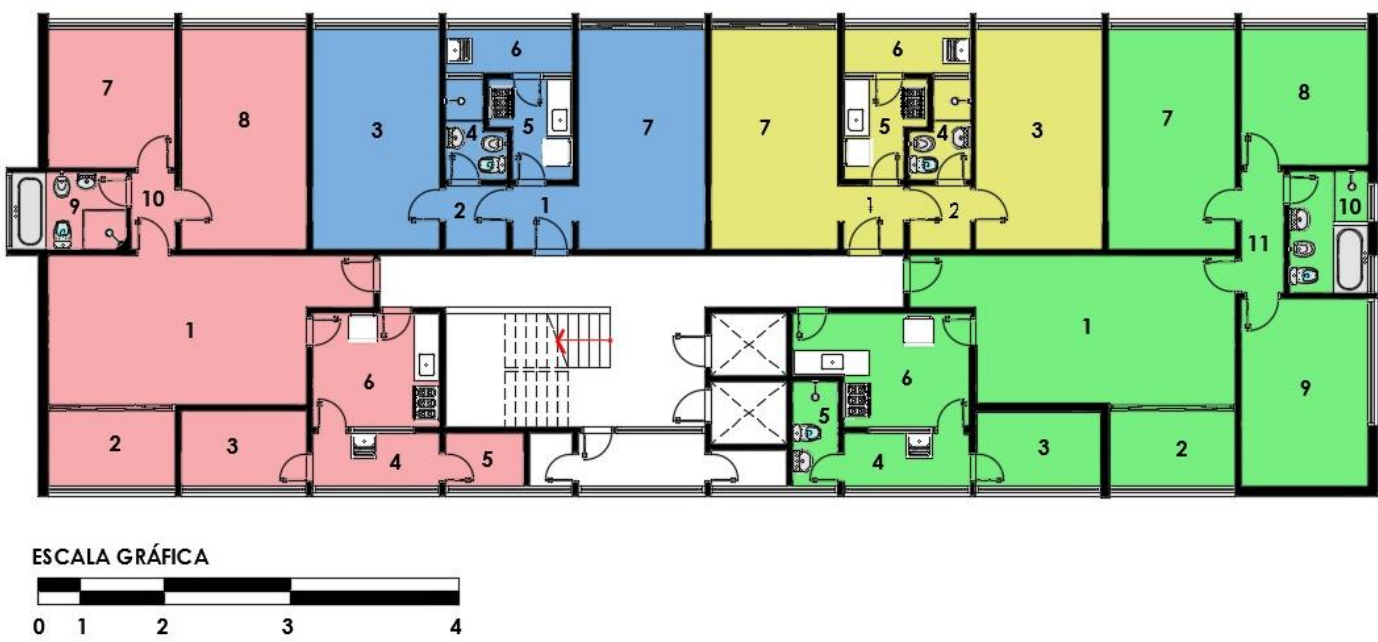

Fonte: AUTORES, 2018

Sendo que, cada tipologia apresenta dimensões variadas, conforme:

Tipologia A (cores: azul e amarelo): (1) vestíbulo ou hall de entrada $\left(2,44 \mathrm{~m}^{2}\right)$; (2) circulação $\left(2,13 \mathrm{~m}^{2}\right)$; (3) dormitório $\left(15,42 \mathrm{~m}^{2}\right)$; (4) banheiro $\left(2,70 \mathrm{~m}^{2}\right)$; (5) cozinha $\left(3,84 \mathrm{~m}^{2}\right)$; (6) área de serviço $\left(3,09 \mathrm{~m}^{2}\right)$; (7) sala $\left(15,69 \mathrm{~m}^{2}\right)$. Área interna total de 45,34 $\mathrm{m}^{2}$.

Tipologia B (cor rosa): (1) sala de estar e jantar (21,83 $\left.\mathrm{m}^{2}\right)$; (2) sacada $\left(5,40 \mathrm{~m}^{2}\right)$; (3) costura ou dormitório de empregada $\left(5,40 \mathrm{~m}^{2}\right)$; (4) área de serviço $\left(3,83 \mathrm{~m}^{2}\right)$; (5) banheiro de empregada (2,34 $\left.\mathrm{m}^{2}\right)$; (6) cozinha $\left(8,10 \mathrm{~m}^{2}\right)$; (7) dormitório 1 (9,84 $\left.\mathrm{m}^{2}\right)$; (8) dormitório 2 (15,42 $\left.\mathrm{m}^{2}\right)$; (9) banho $\left(4,85 \mathrm{~m}^{2}\right) ;(10)$ circulação $\left(1,81 \mathrm{~m}^{2}\right)$. Área interna total de $78,82 \mathrm{~m}^{2}$.

Tipologia C (cor verde): (1) sala de estar e jantar (21,83 $\left.\mathrm{m}^{2}\right)$; (2) sacada $\left(5,40 \mathrm{~m}^{2}\right)$; (3) costura ou dormitório de empregada $\left(5,40 \mathrm{~m}^{2}\right)$; (4) área de serviço $\left(3,83 \mathrm{~m}^{2}\right)$; (5) banheiro de empregada $\left(2,62 \mathrm{~m}^{2}\right)$; (6) cozinha $\left(9,90 \mathrm{~m}^{2}\right)$; (7) dormitório 1 (15,42 $\left.\mathrm{m}^{2}\right)$; (8) dormitório 2 (9,69 m²); (9) dormitório $3\left(15,35 \mathrm{~m}^{2}\right)$; (10) banho $\left(5,36 \mathrm{~m}^{2}\right) ;(11)$ circulação $\left(2,92 \mathrm{~m}^{2}\right)$. Área total interna de $97,72 \mathrm{~m}^{2}$.

\footnotetext{
${ }^{1}$ As identificações dos ambientes e áreas internas dos apartamentos neste trabalho foram coletadas do projeto de restauro de Pauleto (2015).
} 


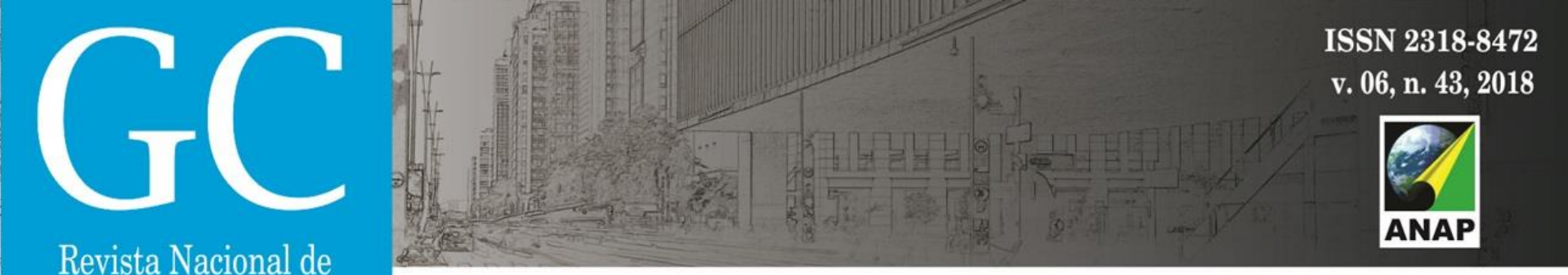

Gerenciamento de Cidades

\subsection{TIPO DE PESQUISA}

A natureza da pesquisa enquadra-se como descritiva, através da metodologia de $A P O$ e $P E$, a partir da análise de um estudo de caso. Para Gil (2002, p. 42) pesquisas descritivas são: “[...] as que habitualmente realizam os pesquisadores sociais preocupados com a atuação prática", que nesse caso, trata-se da qualidade habitacional da arquitetura modernista.

\subsection{POPULAÇÃO E AMOSTRA}

Para identificar o nível de satisfação dos usuários com as unidades de habitação, o universo da pesquisa contemplou os atuais moradores do Edifício Brasil Portugal. A definição da amostra foi feita com base no Painel de Especialistas (PE), que de acordo com Elali e Pinheiro (2013, p. 24): "a quantidade de pessoas não é definida antecipadamente e depende diretamente do problema em análise". O edifício possui o total de 48 apartamentos, no entanto algumas unidades estavam desocupadas (moradores ausentes e apartamentos à venda/locação). Assim, o grupo amostral ${ }^{2}$ ficou constituído por 25 residentes de 25 apartamentos (52,08\% do total das unidades).

\subsection{COLETA DE DADOS}

A coleta de dados ${ }^{3}$ foi desenvolvida através do $P E$, que utiliza da competência dos membros participantes da pesquisa para responder ao que se busca (ELALI; PINHEIRO, 2013). Nesse caso os moradores do edifício são os especialistas.

A técnica utilizada foi o questionário, por ser um meio capaz de "[...] verificar como as pessoas usuárias (consumidores) de um determinado produto, no caso o ambiente construído, o percebem, o utilizam, como a ele se referem, qual o ponto de vista em relação a ele" (ORNSTEIN, 1992, p. 111). Os questionários foram entregues pelos pesquisadores à síndica do edifício, sendo distribuídos e recolhidos dos apartamentos pela zeladora. Portanto, não houve o contato dos pesquisadores com os moradores. O corpo do questionário é composto de questões em formato múltipla escolha, apresentando: identificação da tipologia de apartamento (1 questão); idade do morador (1 questão); tempo de moradia no edifício (1 questão). Contém também questões abertas com relação ao que os moradores mais e menos gostam ( 2 questões) e o que gostariam de mudar no apartamento (1 questão). As demais são fechadas, envolvendo critérios específicos de avalição com relação à iluminação (8 questões),

\footnotetext{
${ }^{2}$ Soube-se da quantidade de participantes (moradores) na pesquisa após o recolhimento do material. Foram entregues o total de 48 questionários impressos para a síndica do prédio.

${ }^{3}$ A coleta de informações foi realizada nas datas: 29 de maio e 8 de junho de 2018, respectivamente, para entrega e recolhimento do material (questionários) pelos pesquisadores.
} 


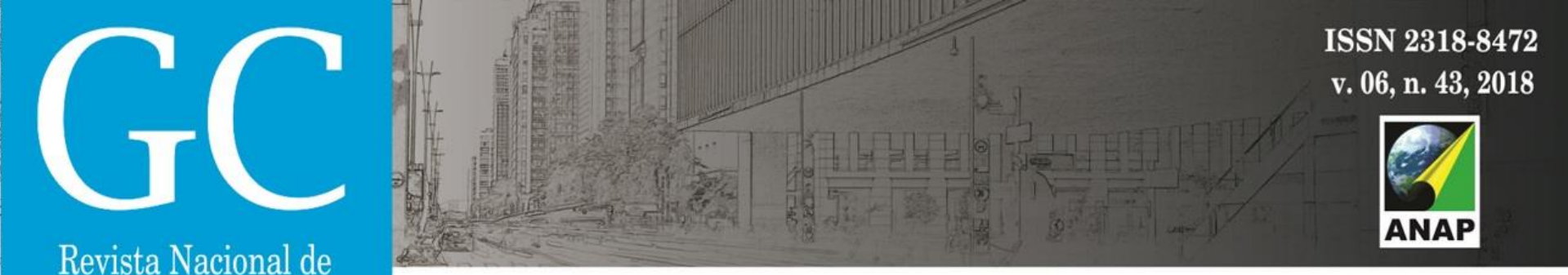

Gerenciamento de Cidades

conforto térmico (4 questões), ventilação (5 questões), acústica (8 questões) e tamanho dos apartamentos (6 questões).

\subsection{ANÁLISE DE DADOS}

As análises são feitas em aspectos qualitativo e quantitativo dos resultados com relação à percepção dos moradores (especialistas), as respostas dos moradores foram analisadas na consideração de maior e menor número das avaliações para cada questão de pergunta fechada. Com relação às questões abertas, utilizou-se como critério o conteúdo mais mencionado nas repostas.

\section{RESULTADOS}

Os resultados estão organizados conforme os critérios elencados para avaliação da qualidade habitacional no objeto de estudo, considerando: tipologias dos apartamentos, características dos moradores, o que mais/menos gostam e o que gostariam de mudar no apartamento (desejos dos moradores). Além da avaliação das condições de iluminação natural, conforto térmico, ventilação natural, acústica, dimensões dos apartamentos e cômodos.

\subsection{TIPOLOGIAS DOS APARTAMENTOS}

Sobre as tipologias de apartamentos, tem-se que $40 \%$ dos moradores ocupam a Tipologia $C$ ( 3 dormitórios), 16\% Tipologia B (2 dormitórios) e 44\% a Tipologia A (1 dormitório). Dados que permitem interpretar que a diversidade tipológica de apartamentos possibilita a reunião de diferentes perfis familiares (solteiros, casais sem filhos, casais com filhos e demais configurações) no mesmo edifício.

\subsection{CARACTERÍSTICAS DOS MORADORES}

As características dos moradores, tem-se com relação às idades das pessoas, que: $36 \%$ encontram-se nas faixas etárias de 61 anos e cima; $20 \%$ entre 45 a 60 anos; $8 \%$ entre 36 a 45 anos; $8 \%$ entre 26 a 35 anos; $28 \%$ entre 15 a 25 anos. A partir desses valores, verifica-se que grande parte dos residentes possuem 61 anos ou mais (idosos), e entre 15 a 25 anos (jovens). Com relação ao tempo de residência dos moradores, $4 \%$ não responderam; $4 \%$ acima de 30 anos; $12 \%$ de 21 a 30 anos; $28 \%$ de 11 a 20 anos; $52 \%$ de 1 a 10 anos. Interpreta-se desses dados, que apesar do edifício datar da década de 60 , poucos são os moradores que residem no local em período superior a 30 anos; uma vez que o maior percentual corresponde aos residentes de 1 a 10 anos de domicílio. 


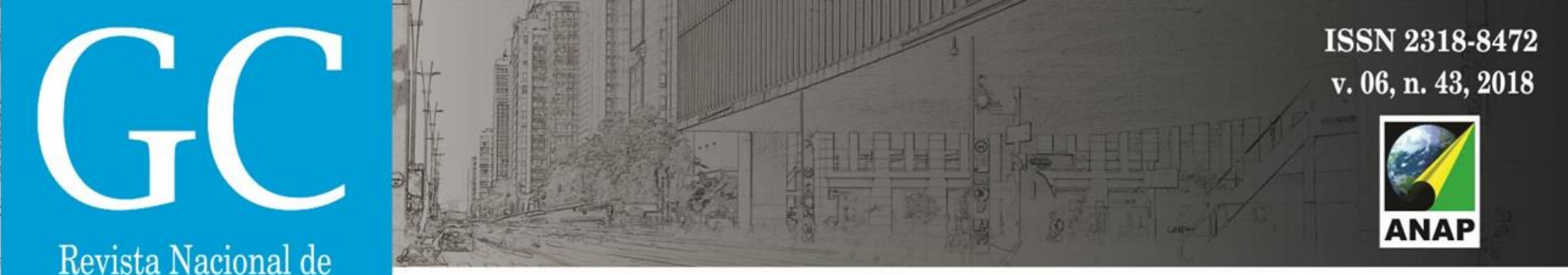

Gerenciamento de Cidades

\subsection{DESEJOS DOS MORADORES}

Ao adotar o critério do PE de maior representatividade das respostas obtida dos moradores, tem-se: sobre o que mais gostam em seus apartamentos: tamanho da unidade; pé-direito alto; iluminação e ventilação natural; vista para a cidade. O que menos gostam: barulho da rua; tamanho da cozinha das unidades de Tipologia A (1 dormitório); tombamento que impossibilita a instalação de máquinas de ar condicionado nas faces do prédio. O que mudariam: troca das janelas (caixilhos) existentes; instalação de ar condicionado nos apartamentos; aparência externa do edifício, no caso da manutenção da pintura das fachadas.

\subsection{ILUMINAÇÃO NATURAL}

As respostas dos moradores com relação às condições de iluminação natural dos apartamentos e dos cômodos são: apartamento ( $8 \%$ regular; $36 \%$ boa; $56 \%$ ótima); dormitórios (s) (24\% boa; $76 \%$ ótima); cozinha (4\% péssima; $8 \%$ ruim; $28 \%$ regular; $20 \%$ boa; $40 \%$ ótima); banheiro (s) (4\% péssima; $4 \%$ ruim; $8 \%$ regular; $36 \%$ boa; $48 \%$ ótima); área de serviço ( $4 \%$ regular; $40 \%$ boa; $56 \%$ ótima). Na pergunta, qual o cômodo que os moradores gostariam que fosse o mais iluminado nos apartamentos ( $48 \%$ indiferente; $8 \%$ sala; $16 \%$ banheiro; $28 \%$ cozinha). Sobre a necessidade de acender lâmpadas durante o dia: $72 \%$ disseram que sim e $28 \%$ que não. E por fim, especificando qual ambiente os moradores precisam acender lâmpadas durante o dia: $14 \%$ disseram o (s) banheiro (s), $72 \%$ cozinha e $14 \%$ sala.

Como resultados, tem-se que todos os ambientes foram classificados como "ótimo". Todavia, para alguns moradores, a cozinha foi o cômodo que mais "depende" do uso da iluminação artificial (lâmpadas), pois apresenta as aberturas voltadas para a área de serviço.

\subsection{CONFORTO TÉRMICO}

As respostas dos moradores com relação ao conforto térmico dos apartamentos, consideram: a temperatura do apartamento durante o verão (56\% agradável; $36 \%$ quente; $8 \%$ muito quente) e inverno ( $60 \%$ agradável; $32 \%$ frio; $8 \%$ muito frio). Já com relação aos cômodos dos apartamentos, o mais desconfortável durante o verão (44\% indiferente; $16 \%$ sala; $28 \%$ cozinha; $12 \%$ dormitórios) e inverno (16\% área de serviço; $12 \%$ banheiro; $36 \%$ indiferente; $16 \%$ sala; $8 \%$ cozinha; $12 \%$ dormitórios). A maior representatividade das respostas dos moradores prevalece a classificação "agradável" para os apartamentos, e "indiferente" para os cômodos. Notando-se, desse modo, a satisfação dos residentes no edifício. 


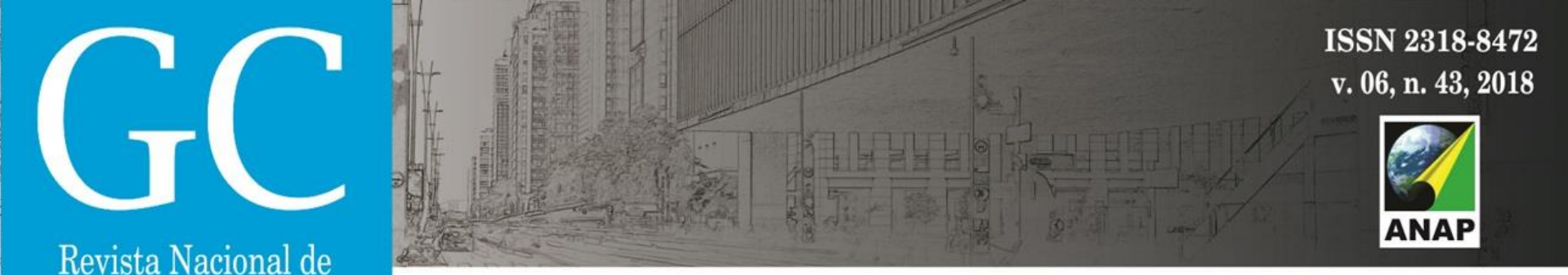

Gerenciamento de Cidades

\subsection{VENTILAÇÃO NATURAL}

As respostas dos moradores no tocante à avaliação da ventilação natural dos cômodos dos apartamentos, foram: sala ( $4 \%$ regular; $32 \%$ boa; $64 \%$ ótima); dormitório (s) (4\% regular; $40 \%$ boa; $56 \%$ ótima); cozinha (4\% indiferente; $4 \%$ ruim; $28 \%$ regular; $32 \%$ boa; $32 \%$ ótima); área de serviço ( $12 \%$ regular; $32 \%$ boa; $56 \%$ ótima). Sobre os ambientes que os residentes gostariam que fossem o mais ventilado naturalmente: $12 \%$ responderam o banheiro; $40 \%$ indiferente; $8 \%$ sala; $20 \%$ cozinha e $20 \%$ dormitório (s).

Como resultado, tem-se que a ventilação natural é um fator que agrada a maioria dos moradores. Verifica-se, no entanto, que apenas a cozinha apresentou avaliação "regular". Classificação semelhante à consideração das condições de iluminação natural da cozinha: ambiente que não recebe iluminação direta da face externa do edifício.

\subsection{ACÚSTICA}

As respostas dos moradores com relação à acústica dos apartamentos são apresentadas nas condições de: ouvir barulhos do apartamento ao lado (28\% nada; $52 \%$ pouco; $12 \%$ moderado; $8 \%$ muito); ouvir barulhos do apartamento de cima (32\% nada; $48 \%$ pouco; $16 \%$ moderado; $4 \%$ muito); ouvir barulhos do apartamento embaixo ( $76 \%$ nada; $16 \%$ pouco; $8 \%$ muito); ouvir barulhos vinda da rua ( $4 \%$ pouco; $44 \%$ moderado; $52 \%$ muito); ambiente que mais incomoda em relação ao barulho da rua ( $8 \%$ área de serviço; $32 \%$ sala; $32 \%$ dormitório; $28 \%$ indiferente); nível que consegue ouvir barulhos vindos de outros cômodos (24\% nada; $52 \%$ pouco; $16 \%$ moderado; $8 \%$ muito); ambiente que mais incomoda em relação ao barulho interno do apartamento (12\% sala; $8 \%$ cozinha; $16 \%$ dormitório (s); $64 \%$ indiferente); barulho que os moradores mais se incomodam ( $16 \%$ indiferente; $8 \%$ vizinhos; $76 \%$ rua).

Dos resultados, tem-se em relevância, que o barulho interno entre os apartamentos vizinhos ou do próprio apartamento não são incômodos. Já o barulho externo, vindo da rua, incomoda $76 \%$ moradores, uma vez que o edifício está situado no cruzamento de duas avenidas (Rodrigues Alves e Nações Unidas) muito movimentadas na cidade de Bauru-SP.

\subsection{DIMENSÕES DOS APARTAMENTOS E CÔMODOS:}

Avaliação com relação as dimensões: apartamento (4\% regular; 33\% bom; $63 \%$ ótimo), dormitório (s) (28\% bom; $72 \%$ ótimo), banheiro (s) (4\% ruim; $8 \%$ regular; $56 \%$ bom; $32 \%$ ótimo), cozinha ( $8 \%$ péssimo; $17 \%$ ruim; $25 \%$ regular; $38 \%$ bom e $12 \%$ ótimo); área de serviço ( $4 \%$ indiferente; $4 \%$ péssimo; $12 \%$ ruim; $28 \%$ regular; $32 \%$ bom; $20 \%$ ótimo) e sala ( $4 \%$ regular; $28 \%$ bom; $68 \%$ ótimo).

Nota-se, que os tamanhos dos apartamentos atendem as expectativas do dia-a-dia dos especialistas (moradores), observando que o determinante das avaliações está relacionado à 
disponibilidade de espaço presente nos ambientes, e não no número de dormitório, uma vez que no edifício existem apartamentos de um quarto (Tipologia A).

\section{CONCLUSÃO}

O objeto e estudo de caso, Edifício Brasil Portugal localizado no município de Bauru-SP, traduz as potencialidades de uma obra modernista da década de 60 que, adequa-se as necessidades dos moradores atuais. O programa e partido arquitetônico adotado por Fernando Pinho, no caso das diferentes tipologias (apartamentos de um, dois e três dormitórios), da implantação no terreno (conforto térmico, iluminação e ventilação natural) e a localização deste na área central da cidade, também são questões a serem consideradas para entender a alta porcentagem de avaliação positiva (satisfação) dos moradores.

Com relação aos procedimentos metodológicos através da APO, no caso de projetos da arquitetura modernista, espera-se que novos processos sejam experimentados afim de identificar quais métodos e técnicas melhor se aplicam para a concepção do ambiente doméstico produzido pelos arquitetos modernistas no Brasil.

\section{AGRADECIMENTOS}

Agradecemos a receptividade dos moradores do Edifício Brasil Portugal, em especial a síndica e a zeladora que possibilitaram o desenvolvimento desta pesquisa, bem como a participação de todos os condôminos presentes que se propuseram a responder os questionários.

\section{REFERÊNCIAS BIBLIOGRÁFICAS}

ARTIGAS, Vilanova. Caminhos da arquitetura. 4. ed. São Paulo: Cosac Naify, 2004. 234 p. Organizado por Rosa Artigas e José Tavares Correia de Lira.

ASSOCIAÇÃO BRASILEIRA DE NORMAS TÉCNICAS - ABNT. NBR 15575/1-5: edifícios habitacionais de até cinco pavimentos. Rio de Janeiro, 2010

BANHAM, Reyner. Teoria e projeto na primeira era da máquina. 3. ed. São Paulo: Perspectiva, 2006. 515 p. Tradução de: A. M. Goldberger Coelho.

BRUAND, Yves. Arquitetura contemporânea no Brasil. 5. ed. São Paulo: Perspectiva, 2010. 398 p. Tradução de: Ana M. Goldberger.

CABRAL, Maria Izabel Rêgo. A EXPRESSÃO DO PENSAMENTO MODERNO DE LINA BO BARDI: UMA ANÁLISE DE ESCRITOS DA ARQUITETA PARA REVISTAS ITALIANAS ENTRE 1940 E 1946. In: O CAMPO AMPLIADO DO MOVIMENTO MODERNO, 11., 2016, Recife. Anais... . Recife: Docomomo, 2016. p. 1 - 12. Disponível em:

<http://www.seminario2016.docomomo.org.br/artigos_publicacao/DOCO_PE_CABRAL.pdf >. Acesso em: 23 jul. 2018.

ELALI, Gleice Azambuja; PINHEIRO, José Q. Analisando a experiência do habitar: algumas estratégias metodológicas. In: VILLA, Simone Barbosa; ORNSTEIN, Sheila Walbe (Org.). Qualidade ambiental na habitação: avaliação pósocupação. São Paulo: Oficina de Textos, 2013. Cap. 1. p. 15-35. 


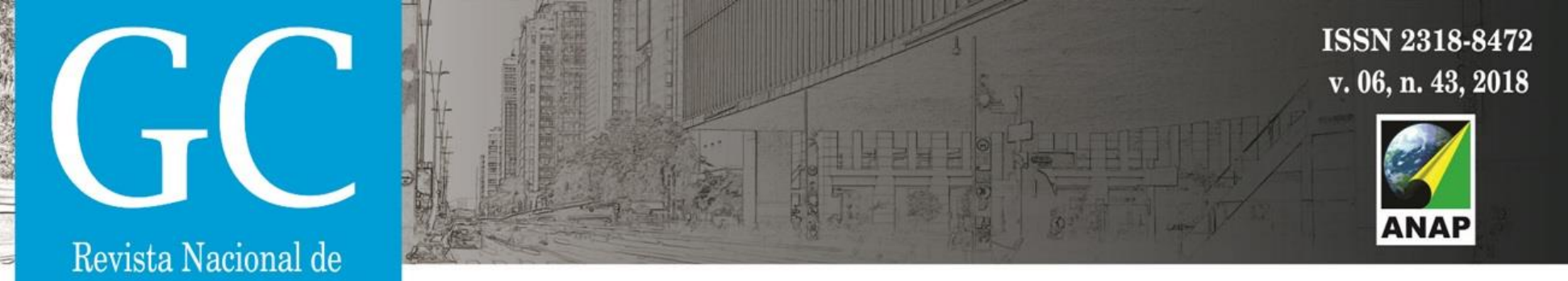

Gerenciamento de Cidades

FERRAZ, Artemis Rodrigues Fontana. Marcas do moderno na arquitetura de Bauru. 2003. 305 f. Dissertação (Mestrado) - Curso de Arquitetura e Urbanismo, Tecnologia do Ambiente Construído, Escola de Engenharia de São Caros - Universidade de São Paulo, São Carlos, 2003.

GALVÃO, Walter José Ferreira. COPAN/SP: a trajetória de um mega empreendimento, da concepção ao uso. Estudo compreensivo do processo com base na Avaliação Pós-Ocupação. 2007. 197 f. Dissertação (Mestrado) - Curso de Arquitetura e Urbanismo, Tecnologia da Arquitetura, Faculdade de Arquitetura e Urbanismo da Universidade de São Paulo, São Paulo, 2007. Disponível em: <http://www.teses.usp.br/teses/disponiveis/16/16132/tde-19092007121207/pt-br.php>. Acesso em: 1 ago. 2018.

GALVÃO, Walter José Ferreira; ORNSTEIN, Sheila Walbe. ANÁLISE DA FUNCIONALIDADE DOS APARTAMENTOS DO EDIFÍCIO COPAN/SP. In: NÚCLEO DE PESQUISA EM TECNOLOGIA DA ARQUITETURA E URBANISMO - O ESPAÇO SUSTENTÁVEL - INOVAÇÕES EM EDIFÍCIOS E CIDADES, 7., 2008, São Paulo. Anais... . São Paulo: Nutau, 2008. p. 1 11. Disponível em: <https://www.usp.br/nutau/CD/129.pdf>. Acesso em: 1 ago. 2018.

GALVÃO, Walter José Ferreira; ORNSTEIN, Sheila Walbe; ONO, Rosário. A avaliação pós-ocupação em empreendimentos habitacionais no Brasil: da reabilitação aos novos edifícios. In: VILLA, Simone Barbosa; ORNSTEIN, Sheila Walbe (Org.). Qualidade ambiental na habitação: avaliação pós-ocupação. São Paulo: Oficina de Textos, 2013. Cap. 2. p. 37-52.

GIL, Antonio Carlos. Como Elaborar Projetos de Pesquisa. 4. ed. São Paulo: Editora Atlas, 2002. 176 p.

GUELLERO, Maria Stela; SALCEDO, Rosío Fernández Baca. AVALIAÇÃO PÓS-OCUPAÇÃO DO EDIFÍCIO RESIDENCIAL BRASIL PORTUGAL, BAURU-SP. In: III COLÓQUIO DE PESQUISAS EM HABITAÇÃO, 3., 2006, Belo Horizonte. Anais... . Belo Horizonte: Grupo de Pesquisa Mom. Morar de Outras Maneiras, 2006. p. 1 - 3. Disponível em:

<http://www.mom.arq.ufmg.br/mom/02_eventos/coloquio2006/textos/maria_guellero_coloquio06.pdf $>$. Acesso em: 01 ago. 2018.

HARVEY, David. CONDIÇõES PÓS-MODERNA: Uma Pesquisa sobre as Origens da Mudança Cultural. 17. ed. São Paulo: Edições Loyola, 2008. 349 p. Tradução de: Adail Ubirajara Sobral e Maria Stela Gonçalves.

MAHFUZ, Edson. 0 sentido da arquitetura moderna brasileira. Arquitextos, São Paulo, ano 02, n. 020.01, Vitruvius, jan. 2002 <http://www.vitruvius.com.br/revistas/read/arquitextos/02.020/811>. Acesso em: 23 jul. 2018.

MEDEIROS, Lótos Dias. Análise da Eficiência Térmica em Conjunto Habitacional: O estudo de caso Zezinho Magalhães Prado - CECAP. 2014. 138 f. Dissertação (Mestrado) - Curso de Arquitetura e Urbanismo, Projeto de Arquitetura e Urbanismo, Universidade Presbiteriana Mackenzie, São Paulo, 2014. Disponível em: <http://tede.mackenzie.br/jspui/bitstream/tede/369/1/Lotos\%20Dias\%20Medeiros.pdf>. Acesso em: 1 ago. 2018.

MOISINHO FILHO, Elso de Freitas. Avaliação Pós Ocupação com Ênfase em Conforto Ambiental em Edifício Residencial projetado pelo Arq. Niemeyer: o Caso do edifício Montreal em São Paulo - SP. In: NÚCLEO DE PESQUISA EM TECNOLOGIA DA ARQUITETURA E URBANISMO - O ESPAÇO SUSTENTÁVEL - INOVAÇÕES EM EDIFÍCIOS E CIDADES, 7., 2008, São Paulo. Anais... . São Paulo: Nutau, 2008. p. 1 - 10. Disponível em: <https://www.usp.br/nutau/CD/155.pdf>. Acesso em: 1 ago. 2018.

ORNSTEIN, Sheila. Avaliação pós-ocupação (APO) do ambiente construído. São Paulo: Editora da Universidade de São Paulo, 1992. 223 p.

PAULETO, Ludmilla Sandim Tidei de Lima. Memorial Descritivo: Restauro do Edifício Brasil-Portugal. Bauru: Tidei de Lima. Projetos, Construções e Consultorias, 2015. 39 p.

PUPIM, Rafael Giácomo. Arquitetura moderna em Bauru: a obra do arquiteto Fernando Ferreira de Pinho. Risco: revista de pesquisa em arquitetura e urbanismo, São Carlos, v. 6, p.22-34, 2007. Semestral. Disponível em: $<$ https://www.revistas.usp.br/risco/search/search?simpleQuery=Arquitetura+moderna+em+Bauru:+a+obra+do+arq uiteto+Fernando+Ferreira+de+Pinho\&searchField=query>. Acesso em: 01 out. 2017.

REQUENA-RUIZ, Ignacio. Thermal comfort in twentieth-century architectural heritage: Two houses of Le Corbusier and André Wogenscky. Frontiers of Architectural Research, [s.I.], v. 5, n. 2, p.157-170, jun. 2016. Elsevier BV. http://dx.doi.org/10.1016/j.foar.2016.02.001. 
Revista Nacional de

Gerenciamento de Cidades

National Journal of Cities Management

RETTO JÚNIOR, Adalberto da Silva. Um Percurso na Obra do Arquiteto Fernando Ferreira Pinho: Geografia de uma Modernidade e Ensaio de Catalogação. In: $5^{\circ}$ SEMINÁRIO DOCOMOMO BRASIL, 5., 2003, São Carlos. Anais... . São Carlos: Docomomo, 2003. p. 1 - 9. Disponível em: <http://docomomo.org.br/wpcontent/uploads/2016/01/002R.pdf>. Acesso em: 11 jun. 2018.

SALCEDO, Rosío Fernández Baca et al. A Arquitetura Moderna na Cidade de Bauru (São Paulo): Projetos do Arquiteto Fernando Pinho. In: SEMINÁRIO DOCOMOMO BRASIL, 3., 1999, São Paulo. Anais... . São Paulo: Docomomo, 1999. p. 1 - 10. Disponível em: <http://docomomo.org.br/wpcontent/uploads/2016/01/Rosio_salcedo.pdf>. Acesso em: 2 ago. 201

VILLA, Simone Barbosa. A ARQUITETURA E O MERCADO IMOBILIÁRIO: ANÁLISE DA PRODUÇÃO DE APARTAMENTOS RECENTES NA CIDADE DE SÃO PAULO. In: I CONFERÊNCIA LATINO-AMERICANA DE CONSTRUÇÃO SUSTENTÁVEL X ENCONTRO NACIONAL DE TECNOLOGIA DO AMBIENTE CONSTRUÍDO, 10., 2004, São Paulo. Anais... . São Paulo: Entac, 2004. p. 1 - 11. Disponível em:

<ftp://ip20017719.eng.ufjf.br/Public/AnaisEventosCientificos/ENTAC_2004/trabalhos/PAP0697d.pdf>. Acesso em: 31 jul. 2018.

VIZONI, Adriano. Edifício Bretagne: Confira detalhes do prédio construído em 1958. 2011. Disponível em: <https://fotografia.folha.uol.com.br/galerias/4898-edificio-bretagne\#foto-91233>. Acesso em: 2 ago. 2018.

ZAPATEL, Juan Antonio. Habitação em Superquadra avaliação Pós-Ocupação (APO). Pós. Revista do Programa de Pós-graduação em Arquitetura e Urbanismo da Fauusp, [s.l.], n. 3, p.53-64, 19 jun. 1993. Universidade de Sao Paulo Sistema Integrado de Bibliotecas - SIBiUSP. http://dx.doi.org/10.11606/issn.2317-2762.v0i3p53-64. Disponível em: <http://www.revistas.usp.br/posfau/article/view/136247/132060>. Acesso em: 1 ago. 2018. 